\title{
Effects of Phosphorus Diffusion on Gettering of Metal Impurities in UMG Silicon Wafers
}

\author{
Sung Yean Yoon, ${ }^{1,2}$ Jeong Kim, ${ }^{1}$ and Kyoon $\mathrm{Choi}^{2}$ \\ ${ }^{1}$ Department of Electronics Engineering, Sejong University, Seoul 143-747, Republic of Korea \\ ${ }^{2}$ KICET Icheon Branch, Korea Institute of Ceramic Engineering and Technology, Icheon 467-843, Republic of Korea \\ Correspondence should be addressed to Jeong Kim; kimjeong@sejong.ac.kr
}

Received 29 January 2013; Accepted 17 October 2013

Academic Editor: Junsin Yi

Copyright (c) 2013 Sung Yean Yoon et al. This is an open access article distributed under the Creative Commons Attribution License, which permits unrestricted use, distribution, and reproduction in any medium, provided the original work is properly cited.

\begin{abstract}
Fe distributions were simulated by using impurity-to-efficiency simulator for the analysis of phosphorus diffusion gettering and confirmed the dependencies of the electron lifetime on the various gettering conditions. It was observed that iron atoms in the $\mathrm{Si}$ wafer could be more efficiently gettered if the temperatures were provided to the wafer in two different steps. That two-step gettering process was applied to an upgraded-metallurgical grade (UMG) Si wafer, and the electron lifetimes of the UMG-Si wafer were $3 \mu$ sec by applying the second temperature profile at $600^{\circ} \mathrm{C}$ for $420 \mathrm{~min}$. It was also confirmed that the efficiency of the UMG-Si solar cell increased $0.53 \%$ due to two-step gettering process.
\end{abstract}

\section{Introduction}

In order to reduce manufacturing costs, solar cells are usually produced with a multicrystalline silicon wafer, which inherently contains many impurity atoms and defects. In addition, many researchers have proposed that a further decrease in manufacturing costs could be obtained by using a UMG silicon wafer for the crystalline silicon solar cell [1]. However, more impurity atoms and defects remain in the cost-effective UMG silicon wafer than in the usual multicrystalline silicon wafer. UMG silicon wafers with $5 \mathrm{~N}$ purity include various kinds of transition-metal impurities. The high impurity concentration does not allow for the direct use of the UMG-Si wafers for solar cells. Thus, a variety of efforts have been devoted to increasing the purity of the UMG-Si wafers to the level of solar-grade silicon (SG$\mathrm{Si}$ ) wafers [2]. Transition-metal impurities, such as $\mathrm{Fe}, \mathrm{Ni}$, $\mathrm{Cu}$, and $\mathrm{Co}$, severely degrade the charge carrier lifetime by forming recombination centers in the band gap. Due to the generally high charge carrier recombination activity of transition metals and their precipitates, the presence of such contamination may limit the electrical performance of UMGSi wafers and solar cells [3]. Generally UMG-Si is three orders of magnitude less pure compared with electrical-grade silicon
(EG-Si), but the performance of high-quality UMG-Si solar cells has been demonstrated to be comparable to that of typical EG-Si counterparts [4].

The gettering process has been a widely used method for reducing unintentional metal impurities in the electrically active zones of semiconductor devices. In addition to extrinsic gettering by means of phosphorus diffusion, various alternative methods such as scratching, sand-blasting, and ion implantation of various elements have been developed. Phosphorus diffusion gettering, which can efficiently reduce transition-metal impurities in the bulk of UMG-Si wafers and enhance the charge carrier lifetime, is a well-known process for improving the performance of solar cells in the PV industry [5].

In spite of the enormous studies on the phosphorus gettering process, a clear explanation on the mechanism has not been announced so far. However, it was confirmed experimentally [6] and theoretically $[7,8]$ that the segregation of iron to phosphorus doped layer was the main factor to determine the efficacy of the phosphorus diffusion gettering. Hofstetter et al. developed the impurity-to-efficiency (I2E) simulation tool and calculated changes in the distribution of iron and phosphorus atoms during annealing [9]. In the simulation with I2E simulator, iron is considered as 
the dominant lifetime-limiting impurity, and this approximation is accurate in many regions of a standard mc-Si ingot. The I2E simulator was also used to predict the final solar cell performance with given inputs of material quality, cell processing conditions, and cell architecture.

In this study, a phosphorus diffusion process was employed to getter the metal impurities in UMG-Si wafers. The distribution of iron atoms, the charge carrier lifetime of the UMG-Si wafer, and the efficiency of the cell were compared with the predicted values from the I2E simulator.

A double side emitter was formed by using a $\mathrm{POCl}_{3}$ source to diffuse phosphorus at the front and back sides of UMG-Si wafers. An increase in the electron lifetime was confirmed by using the quasisteady state photoconductivity (QSSPC) measurement, and the efficiency of the UMG-Si solar cells was measured to determine the effectiveness of phosphorus diffusion gettering.

\section{Experiments}

P-type UMG-Si wafers with areas of $2.54 \mathrm{~cm} \times 2.54 \mathrm{~cm}$ and thicknesses of $180-220 \mu \mathrm{m}$ were used. The particles and the organic compounds on their surfaces were removed with RCA-1 solution mixed with $\mathrm{NH}_{4} \mathrm{OH}, \mathrm{H}_{2} \mathrm{O}_{2}$, and deionized (DI) water. The surface texturing was carried out using $\mathrm{HNO}_{3}$ and $\mathrm{HF}$ solutions, and the metal impurities on the surface were removed using RCA-2 solution mixed with $\mathrm{HCl}$, $\mathrm{H}_{2} \mathrm{O}_{2}$, and DI water. The $\mathrm{n}^{+}$emitter was formed by diffusing phosphorus into the wafer in a tube furnace. Phosphorus diffusion was performed by using liquid $\mathrm{POCl}_{3}$ as the dopant source carried by $\mathrm{N}_{2}$ gas. The temperature and time were varied in the ranges of $600-850^{\circ} \mathrm{C}$ and $0-550 \mathrm{~min}$ during phosphorus diffusion. The effects of time and temperature on the MCLTs of the silicon wafers were compared with the values after the standard diffusion which generally processed at $850^{\circ} \mathrm{C}$ for $10 \mathrm{~min}$. Phosphorus silicate glass (PSG) formed after phosphorus diffusion was removed by dipping the wafer in a $0.1 \mathrm{M}$ HF solution for 40 seconds, and the emitter sheet resistance was measured using the four-point probe method. An antireflection coating (ARC) of silicon nitride $\left(\mathrm{SiN}_{x}: \mathrm{H}\right)$ with a thickness of approximately $70 \mathrm{~nm}$ was then deposited by using a plasma-enhanced chemical vapor deposition (PECVD) in order to reduce the surface recombination velocity. The rear surface of the silicon wafer was also passivated by depositing the same $\operatorname{SiN}_{x}: \mathrm{H}$ film for the measurements of the QSSPC. The surface passivation by using iodine was also performed, but significant differences were not obtained compared with the passivation method by using the PECVD$\mathrm{SiN}_{x}: \mathrm{H}$ film. An aluminum layer with a thickness of about $2 \mu \mathrm{m}$ for the back contact of the cell was deposited by RFsputtering, and a silver electrode was formed on the front side by screen-printing. The RF-sputtered aluminum layer and the screen-printed silver were fired using a belt furnace at $800^{\circ} \mathrm{C}$ to form the front and back contacts.

The average characteristics of the electron lifetime were obtained by using the QSSPC measurement system: a Sinton WCT-120 tester according to the carrier density at an injection level of $2 \times 10^{14} \mathrm{~cm}^{-3}$. After gettering process, impurities in the bulk of the wafer move to the surface region. And, before measuring the electron lifetime, the surface of the UMG-Si was removed by chemical etching.

\section{Simulation Process}

The typical Fe concentration in the UMG silicon wafer was reported to be $27 \pm 8$ ppmw by Degoulange et al. [10]. Some of these iron atoms exist at the interstitial sites or $\mathrm{Fe}-\mathrm{B}$ pairs, and the rest of the iron atoms remained as precipitates in the wafer. During the solar cell fabrication process at high temperature, iron atoms in the bulk of the silicon wafer segregate to a diffused phosphorus layer and are dissolved from iron silicide precipitates. Figure 1 shows the I2E simulation results for the distribution of phosphorus and $\mathrm{Fe}$ concentrations after the gettering process at $700^{\circ} \mathrm{C}$ for $300 \mathrm{~min}$. The phosphorus concentration on the surface of the wafer was set to $3 \times 10^{20}$ atoms $/ \mathrm{cm}^{3}$ and the initial concentrations of Fe were $1 \times 10^{15}$ and $1 \times 10^{12}$ atoms $/ \mathrm{cm}^{3}$ for the total and the interstitial Fe concentrations, respectively. That initial value of the total Fe concentration was assumed considering the total Fe concentration in the UMG-Si wafer. The segregation of iron atoms is described by Gafiteanu et al. [11] as

$$
\frac{\partial C_{i}}{\partial t}=\frac{\partial}{\partial x}\left[D_{\mathrm{Fe}}\left(\frac{\partial C_{i}}{\partial x}-\frac{C_{i}}{\sigma} \frac{\partial \sigma}{\partial x}\right)\right],
$$

where $C_{i}$ is the dissolved iron concentration, $D_{\mathrm{Fe}}$ is the temperature-dependent diffusion coefficient of iron in silicon, and $x$ is the depth from the surface of the wafer. The first term on the right represents Fick's law of diffusion, while the second term involves a space-dependent segregation coefficient, $\sigma(x)$, which is characterized by the reactions between Fe interstitials, Si vacancies, and P dopant atoms [12]. Also, the dissolution of precipitated iron atoms is modeled by Ham's law [13]:

$$
\frac{\partial C_{i}}{\partial t}=4 \pi N r D_{\mathrm{Fe}}\left(C_{\mathrm{eq}, \mathrm{Fe}}-C_{i}\right),
$$

where $N$ is the precipitate density, $r$ is the precipitate radius, and $C_{\mathrm{eq}, \mathrm{Fe}}$ is the temperature-dependent solid solubility of iron in silicon. The dissolved iron atoms from the precipitated sites diffused to the $\mathrm{P}$-abundant region, and the distribution of the Fe concentration in the Si evolved as shown in Figure 1. Secondary ion mass spectroscopy (SIMS) analysis was used to confirm the real distribution of iron atoms in the UMGSi wafer annealed at $700^{\circ} \mathrm{C}$ for 5 hours after the P-diffusion process, as shown in Figure 1(e). The difference to the simulation results was mainly from the higher concentration of iron atoms in the UMG-Si and the slightly different gettering temperature and time.

After calculating the Fe distribution in the silicon, the I2E simulator determines electron and hole lifetime throughout the wafer thickness. Shockley-Read-Hall recombination is represented by the charge carrier lifetime [14] as

$$
\frac{1}{\tau_{i}}=C_{i} \sigma_{c} v_{\mathrm{th}},
$$




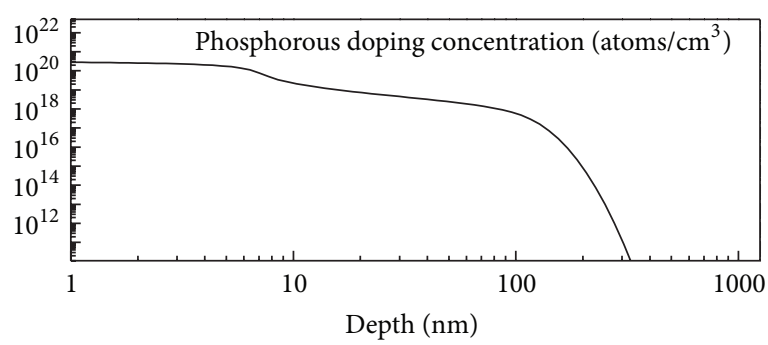

(a)

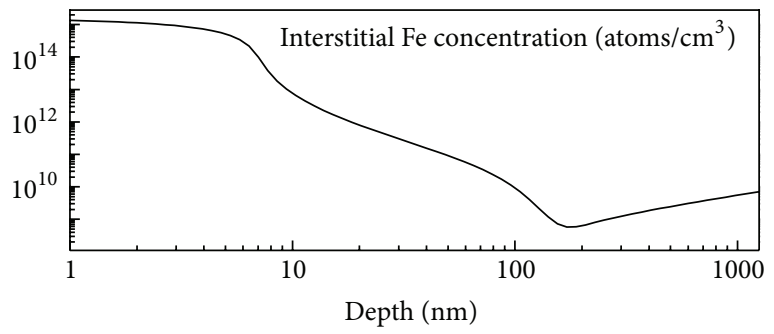

(c)

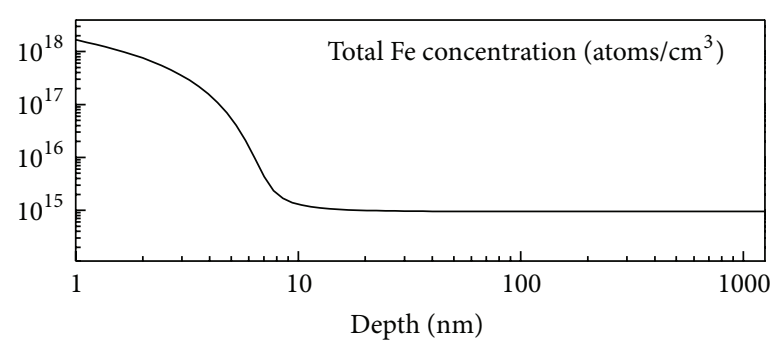

(b)

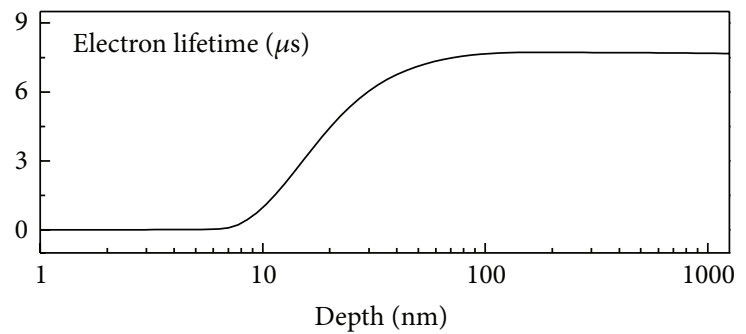

(d)

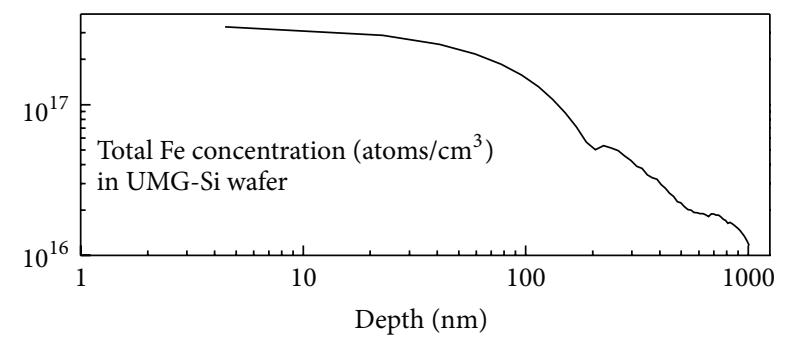

(e)

FIgURE 1: Calculated distributions of $\mathrm{P}$ dopant concentration, total Fe concentration, interstitial Fe concentration, and electron lifetime (from the upper graph) after the gettering process at $700^{\circ} \mathrm{C}$ for $30 \mathrm{~min}$. The lowest graph is the bulk Fe concentration by means of SIMS measurement of the UMG-Si gettered at $700^{\circ} \mathrm{C}$ for 5 hours.

where $\tau_{i}$ is the minority carrier lifetime limited by interstitial iron or Fe-B pairs, $\sigma_{c}$ is the minority carrier capture cross section, and $v_{\text {th }}$ is the thermal velocity of minority carriers. Recombination at iron silicide precipitates also contributes to the charge carrier lifetime by the following expression [15]:

$$
\frac{1}{\tau_{p}}=4 \pi r^{2} N \frac{s D / r}{s+D / r},
$$

where $\tau_{p}$ is the minority carrier lifetime limited by precipitates, $D$ is the minority carrier diffusion length in silicon, and $s$ is the carrier recombination velocity at the precipitate surface. Figure $1(\mathrm{~d})$ shows the electron lifetime obtained using the I2E simulator under the distributions of the $\mathrm{P}$ and Fe concentrations. In the figure, the electron lifetime was confirmed to be determined largely from the Fe concentration in the silicon. However, it is not clear which is the main factor between the total and the interstitial $\mathrm{Fe}$ concentrations in Figure 1.

\section{Results and Discussion}

Figure 2 shows the simulation results of the total Fe concentration averaged throughout the Si wafer after the gettering process. The initial concentrations of the total and the interstitial iron atoms were assumed to be $1 \times 10^{15}$ and $1 \times$ $10^{12}$ atoms $/ \mathrm{cm}^{3}$, respectively, and uniformly distributed in the wafer. The total Fe concentration reduced almost linearly with the gettering time, and the reduction rate rapidly increased with the temperature, which was due to the diffusion of iron atoms to the P-abundant surface layer in the Si wafer.

On the other hand, the dependence on the temperature of the interstitial Fe concentration was different from that of the total $\mathrm{Fe}$ concentration as shown in Figure 3. At the gettering temperature of $750^{\circ} \mathrm{C}$ the interstitial Fe concentration slightly increased and then was saturated along with the time. However, at gettering temperatures above $750^{\circ} \mathrm{C}$, the rapid increases within a few minutes were observed for the interstitial Fe concentrations. The interstitial Fe concentration in the Si wafers processed below $750^{\circ} \mathrm{C}$ decreased with elapsed time and was finally saturated as shown in Figure 3. In the case of the single-crystalline silicon, the amount of the iron atoms transferred to the interstitial sites is very small compared to those that moved to the diffused phosphorus layer from the interstitial sites, due to the initially low concentration of iron atoms in the bulk. Meanwhile, there are several orders of magnitude more iron atoms in the UMG-Si at interstitial 


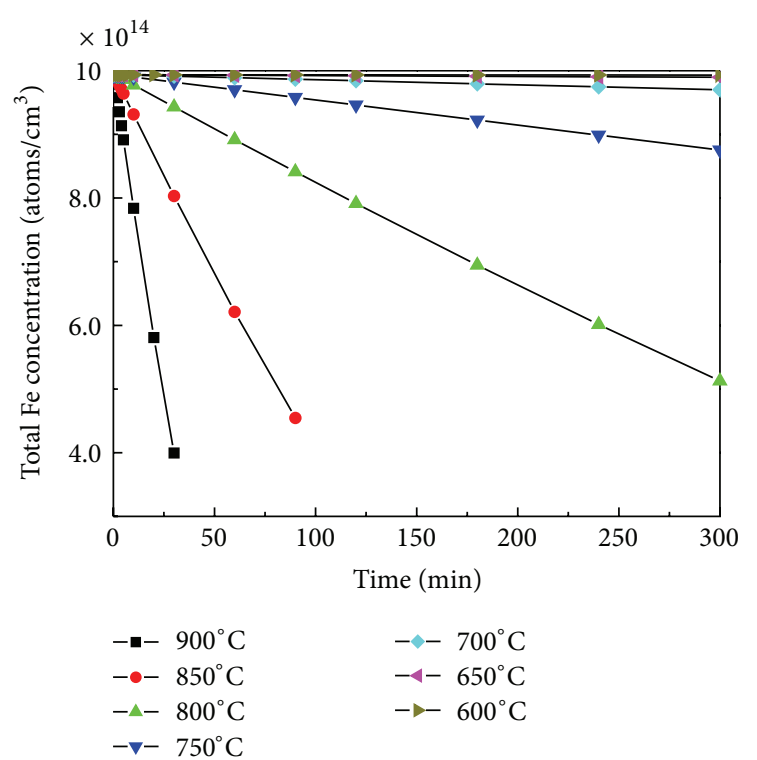

FIgURE 2: Calculated total Fe concentration averaged throughout the $\mathrm{Si}$ wafer after the gettering process with different temperatures and times. The initial concentration of the total iron atoms was assumed to be $1 \times 10^{15}$ atoms $/ \mathrm{cm}^{3}$. The total $\mathrm{Fe}$ concentration decreased more rapidly with gettering time for higher temperature.

or nondissolved precipitate sites in the bulk, compared with those in the single-crystalline silicon. This means that the amount of the iron atoms transferred to the interstitial sites competes with that moved to the diffused phosphorus layer from the interstitial sites and the interstitial Fe concentration may increase at the high gettering temperature in case of the $\mathrm{Si}$ wafer with a large amount of iron atoms.

Equations (3) and (4) assert that the charge carrier lifetime in the Si wafer is determined from the distribution of the Fe concentrations, which exist at the interstitial sites or as precipitates. Figure 4 shows the averaged electron lifetime calculated from the distributions of the iron atoms. Comparing with the Fe concentrations in Figures 2 and 3, it is clear that the electron lifetime was strongly dependent on the interstitial Fe concentration but not on the total Fe concentration. Most of the iron atoms precipitated in the $\mathrm{Si}$ wafer did not directly affect the charge carrier lifetime. On the other hand, only a portion of the iron atoms at the interstitial sites mainly determined the charge carrier lifetime in the Si wafer. This means that the reduction of the interstitial Fe concentration is more important to enhance the charge carrier lifetime and the efficiency of the solar cell.

In order to efficiently getter iron atoms and increase the charge carrier lifetime, a two-step gettering process was introduced in this study. The two-step gettering process involves an annealing process at a high temperature followed by a similar annealing process at a lower temperature. In this simulation, the first step of the temperature profile was fixed to $850^{\circ} \mathrm{C}$ and $30 \mathrm{~min}$, and the temperature and the time were varied during the second step of the gettering process. Figure 5 shows the interstitial $\mathrm{Fe}$ concentration and the electron lifetime with the temperature and the time during

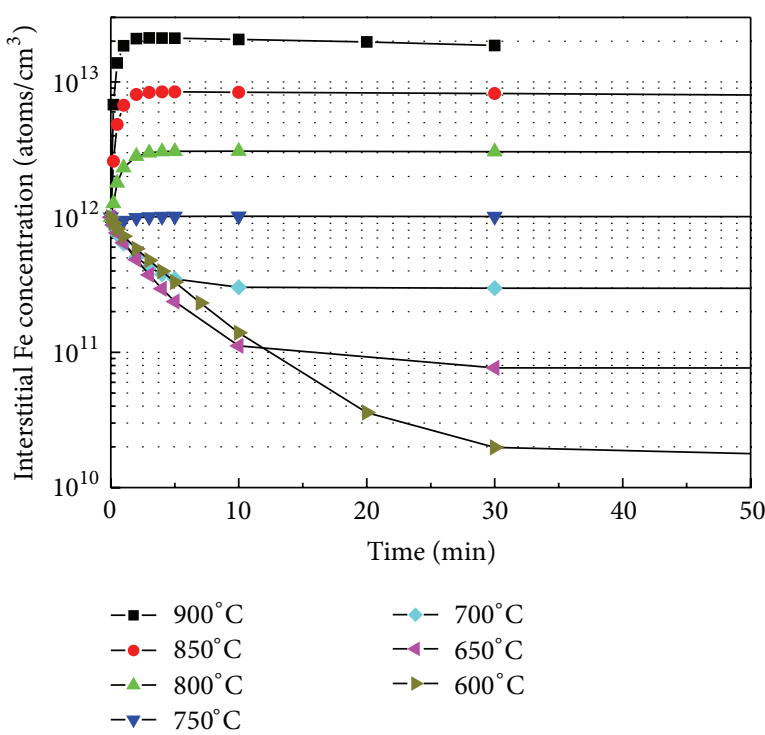

FIGURE 3: Calculated interstitial Fe concentration averaged throughout the Si wafer after the gettering process with different temperatures and times. The initial concentration of the interstitial iron atoms was assumed to be $1 \times 10^{12}$ atoms $/ \mathrm{cm}^{3}$. For higher temperatures than $750^{\circ} \mathrm{C}$, the interstitial Fe concentration increased with time, which might be originated from the increase of iron atoms migrated from the precipitate sites at higher temperature.

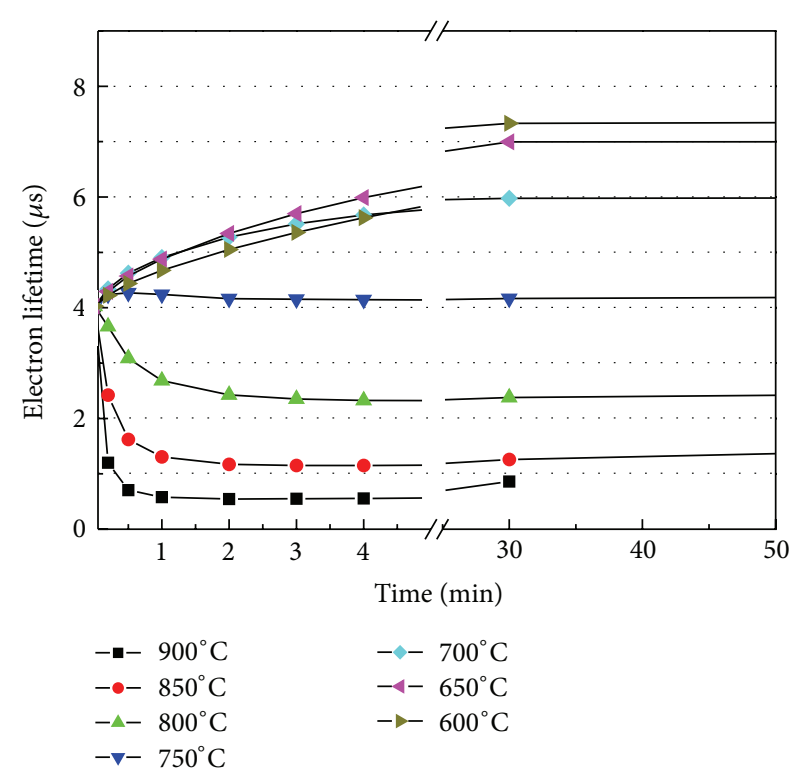

FIGURE 4: Variation of the averaged electron lifetime calculated from the distributions of iron atoms using I2E simulator. It was strongly dependent on the distribution of the interstitial Fe concentration.

the second step of the gettering process. The duration time of the second step was $30 \mathrm{~min}$ for the analysis of the temperature dependency (Figure 5(a)), and the evolution of the interstitial Fe concentration and the electron lifetime with the gettering time of the second step was simulated at the temperature of $600^{\circ} \mathrm{C}$ (Figure 5(b)), where iron atoms were most efficiently 


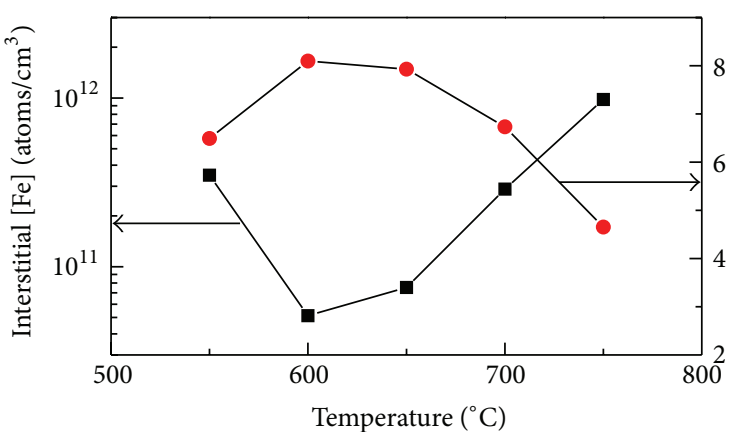

(a)

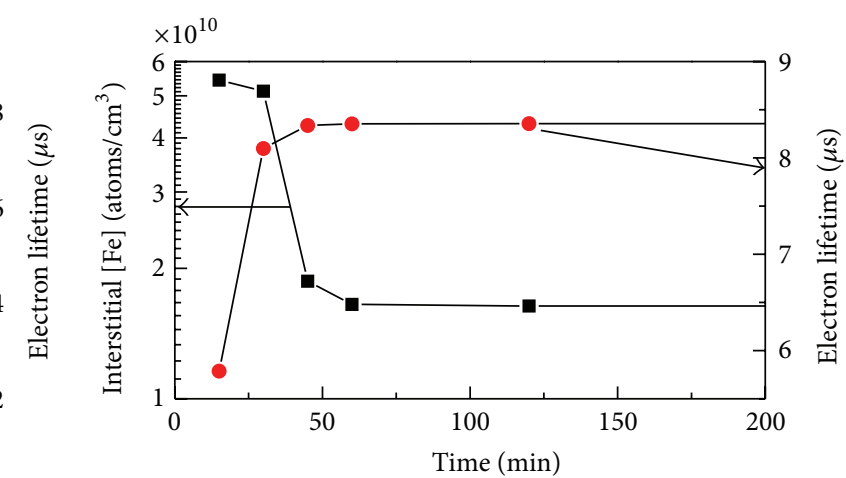

(b)

FIGURE 5: Calculated interstitial Fe concentration and the electron lifetime with (a) the temperature and (b) the time during the second step of the gettering process. The electron lifetime showed the highest value at the temperature of $600^{\circ} \mathrm{C}$, where the interstitial Fe concentration indicated the lowest value. On the other hand, with the increase of the time they were saturated above $50 \mathrm{~min}$.

gettered. The interstitial Fe concentration reached below $2 \times$ $10^{10}$ atoms $/ \mathrm{cm}^{3}$, and the electron lifetime was more than $8 \mu$ sec. Compared with the results of Figure 4, the two-step gettering process was evidently more advantageous for the UMG-Si wafer.

Figure 6 shows the electron lifetime of the UMG-Si wafer processed with the two-step gettering. The first step of the temperature profile was fixed to $850^{\circ} \mathrm{C}$ and $50 \mathrm{~min}$. During the second step, the temperature varied between 600 and $750^{\circ} \mathrm{C}$ for $420 \mathrm{~min}$ (Figure 6(a)) and also the gettering time increased to $540 \mathrm{~min}$ at the temperature of $600^{\circ} \mathrm{C}$. Aside from the measured values of the electron lifetime, the overall behavior was very similar to the simulated electron lifetime as shown in Figure 5. The electron lifetime of the bare UMG-Si wafer was about $1 \mu$ sec and slightly increased to $1.5 \mu \mathrm{sec}$ after only the first temperature profile of the twostep gettering process. A further increase in the electron lifetime to $3 \mu$ sec could be obtained by applying the second temperature profile at $600^{\circ} \mathrm{C}$ for $420 \mathrm{~min}$. The difference in the values between the simulated and observed electron lifetime was originated from the higher total concentration of iron atoms in the UMG-Si wafer than in the sample assumed in this simulation. The grain boundaries in the UMG-Si wafer might be considered as the most important source of the impurities and act as precipitate sites. During the gettering process at high temperature, the precipitated iron atoms in the grain boundaries diffused into the interstitial sites and limited the further increase of the electron lifetime of the UMG-Si wafer.

Figure 7 shows the $I-V$ characteristics of the UMG-Si solar cells processed with one-step and two-step gettering. The efficiency of the cell with one-step gettering was 9.67\%, and two-step gettering improved the efficiency of the cells to $10.2 \%$. In this study, the fabrication process of the crystalline silicon solar cell was not optimized for the high-efficiency cell; instead the effect of phosphorus diffusion gettering on the efficiency of the cell was the main concern. The increase in the cell efficiency due to two-step gettering was $0.53 \%$, which was largely due to increases in the short circuit current density, $J_{\mathrm{sc}}$. On the other hand, open circuit voltage, $V_{\mathrm{oc}}$, of the cell processed with the two-step gettering did not increase compared with $V_{\text {oc }}$ of the cell processed with the one-step gettering in spite of the increase of the electron lifetime immediately after the gettering process. The two-step gettering was very effective to enhance the electron lifetime of the silicon wafer, which was due to the decrease of the interstitial $\mathrm{Fe}$ concentration not of the total Fe concentration. Thus, during the cell fabrication process at the high temperature after the gettering process, the interstitial $\mathrm{Fe}$ concentration which was closely related to the electron lifetime of the wafer might increase and $V_{\text {oc }}$ of the cell was not improved for the twostep gettering. This means that the low-temperature process is very important after the gettering process, especially for the UMG Si wafer which contains a large amount of impurities. Lin et al. reported that the gettering process may improve the diffusion length of a cell but had little influence on the efficiency of the cell [16], and the one-step gettering may also provide a gettering effect on the UMG-Si wafers. This points to the difficulties in obtaining a high-efficiency cell with lowquality material like the UMG-Si wafer.

\section{Conclusion}

In this work, the Fe distribution and the electron lifetime of the $\mathrm{Si}$ wafer were calculated using I2E simulator for the analysis of phosphorus diffusion gettering. The total Fe concentration in the bulk of the Si wafer decreased with gettering time at the whole temperature range of 600$900^{\circ} \mathrm{C}$ suggested in this simulation scheme. Also, the total Fe concentration decreased more rapidly with gettering time for higher temperature. On the other hand, the interstitial Fe concentration, which largely determined the charge carrier lifetime in the Si wafer, increased with the gettering time at temperatures above $750^{\circ} \mathrm{C}$ and was saturated within a few minutes. In order to enhance the efficiency of the gettering, the two-step gettering process was introduced. The first step of the temperature profile at $850^{\circ} \mathrm{C}$ was followed by 


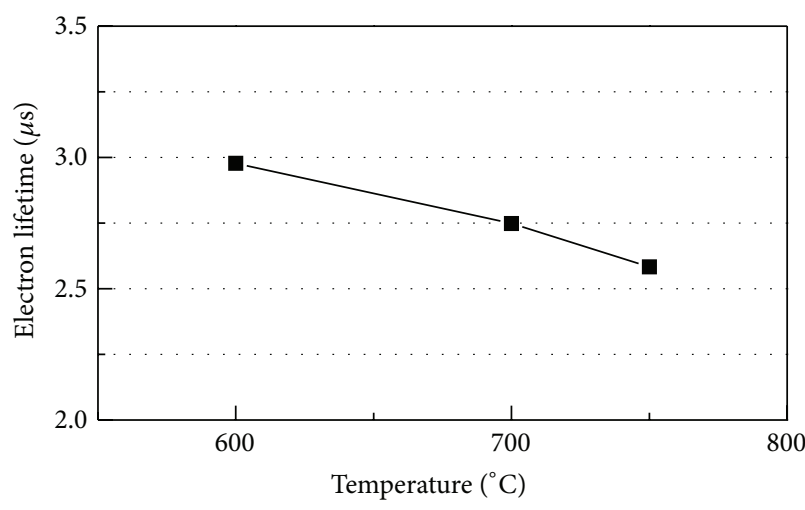

(a)

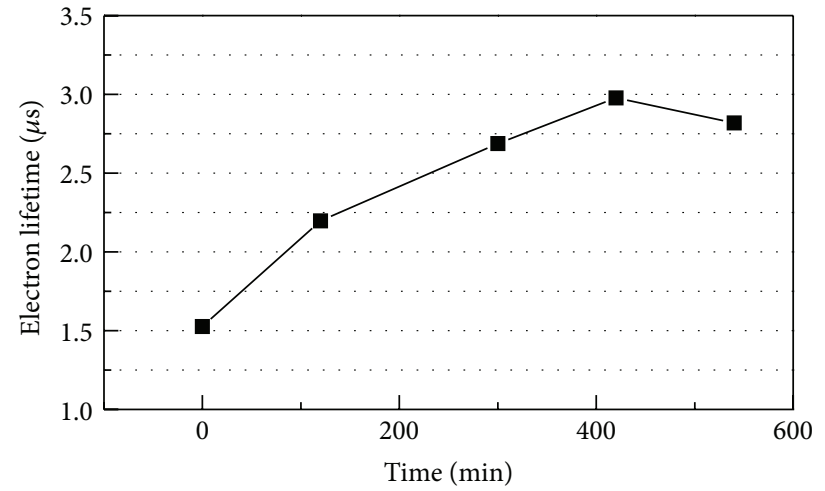

(b)

FIGURE 6: Electron lifetime of the UMG-Si wafer processed with two-step gettering. The first step of the temperature profile was fixed to $850^{\circ} \mathrm{C}$ and $50 \mathrm{~min}$, and during the second step (a) the temperature and (b) the time were varied. The highest electron lifetime was obtained at $600^{\circ} \mathrm{C}$ for $420 \mathrm{~min}$.

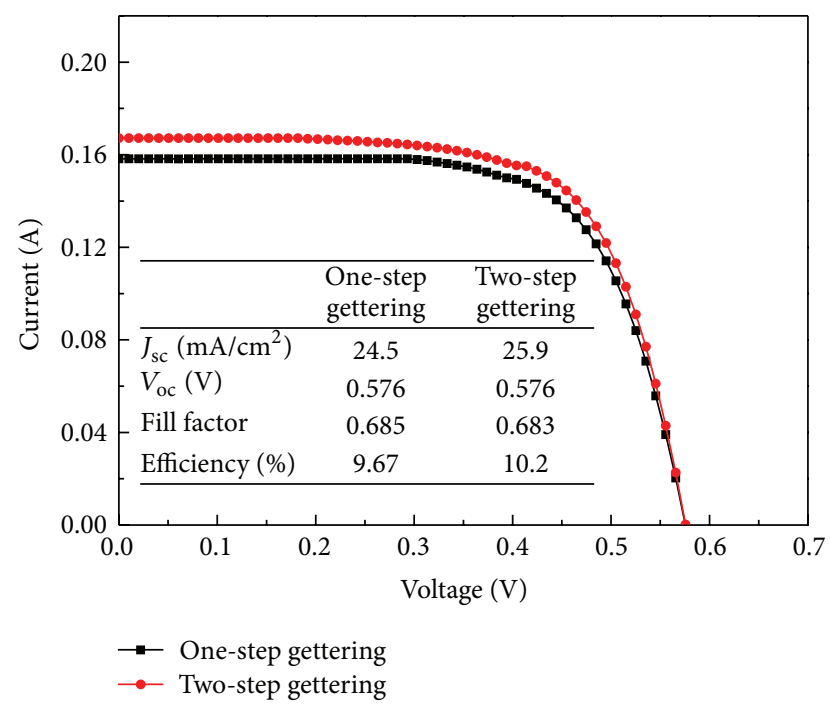

FIGURE 7: $I-V$ characteristics of the UMG-Si solar cells processed with one- and two-step gettering. The increase in the cell efficiency due to two-step gettering was $0.53 \%$ compared with that from onestep gettering.

the second step at a lower temperature. At temperature of $600^{\circ} \mathrm{C}$ for the second step, the electron lifetime was optimized to $8 \mu \mathrm{sec}$. This two-step gettering process was applied to the UMG-Si wafer, and it was observed that the electron lifetime of the UMG-Si wafer increased to $3 \mu \mathrm{sec}$ after the two-step gettering process, compared with the electron lifetime of $1.5 \mu \mathrm{sec}$ after the one-step gettering process. The improvement of the electron lifetime had a significant effect on the efficiency of the UMG-Si solar cell, and the increase in the cell efficiency due to two-step gettering process was $0.53 \%$ compared with that from one-step gettering process.

\section{Acknowledgment}

This work was supported by the New \& Renewable Energy Technology Development Program of the Korea Institute of Energy Technology Evaluation and Planning (KETEP) Grant funded by the Korean Government Ministry of Knowledge Economy (no. 20113010010140).

\section{References}

[1] S. De Wolf, J. Szlufcik, Y. Delannoy, I. Périchaud, C. Häßler, and R. Einhaus, "Solar cells from upgraded metallurgical grade (UMG) and plasma-purified UMG multi-crystalline silicon substrates," Solar Energy Materials and Solar Cells, vol. 72, pp. 49-58, 2002.

[2] K. Prettyman and G. Pfeiffer, "Solar cell production using UMG silicon," in Proceedings of the 24th EUPVSEC, p. 21, Hamburg, Germany, 2009.

[3] A. Bentzen and A. Holt, "Gettering of transition metal impurities during phosphorus emitter diffusion in multicrystalline silicon solar cell processing," Journal of Applied Physics, vol. 99, Article ID 093509, 2006.

[4] D. Kohler, B. Raabe, S. Braun, S. Seren, and G. Hahn, "Upgraded metallurgical-grade silicon solar cells: a detailed material analysis," in Proceedings of the 24th EUPVSEC, p. 1758, Hamburg, Germany, 2009.

[5] H. Nagel, A. G. Aberle, and S. Narayanan, "Method for the evaluation of the influence of gettering and bulk passivation on non-uniform block-cast multicrystalline Si solar cells," Solid State Phenomena, vol. 67-68, pp. 503-508, 1999.

[6] M. B. Shabani, T. Yamashita, and E. Morita, "Study of gettering mechanisms in silicon: competitive gettering between phosphorus diffusion gettering and other gettering sites," Solid State Phenomena, vol. 131-133, pp. 399-404, 2008.

[7] A. A. Istratov, W. Huber, and E. R. Weber, "Modeling of competitive gettering of iron in silicon integrated circuit technology," Journal of the Electrochemical Society, vol. 150, no. 4, pp. G244G252, 2003.

[8] M. Seibt, A. Sattler, C. Rudolf, O. Voß, V. Kveder, and W. Schröter, "Gettering in silicon photovoltaics: current state and 
future perspectives," Physica Status Solidi A, vol. 203, no. 4, pp. 696-713, 2006.

[9] J. Hofstetter, D. P. Fenning, M. I. Bertoni, J. F. Lelievre, C. del Canizo, and T. Buonassisi, "Impurity-to-efficiency simulator: predictive simulation of silicon solar cell performance based on iron content and distribution," Progress in Photovoltaics, vol. 19, pp. 487-497, 2011.

[10] J. Degoulange, I. Périchaud, C. Trassy, and S. Martinuzzi, "Multicrystalline silicon wafers prepared from upgraded metallurgical feedstock," Solar Energy Materials and Solar Cells, vol. 92, no. 10, pp. 1269-1273, 2008.

[11] R. Gafiteanu, U. Gosele, and T. Y. Tan, "Phosphorus and aluminum gettering of gold in silicon: simulation and optimization considerations," in Proceedings of the MRS Spring Meeting, pp. 297-302, April 1995.

[12] A. Haarahiltunen, H. Savin, M. Yli-Koski, H. Talvitie, and J. Sinkkonen, "Modeling phosphorus diffusion gettering of iron in single crystal silicon," Journal of Applied Physics, vol. 105, no. 2, Article ID 023510, 2009.

[13] F. Ham, "Theory of diffusion-limited precipitation," Journal of Physics and Chemistry of Solids, vol. 6, pp. 335-351, 1958.

[14] J. Nelson, The Physics of Solar Cells, Imperial College Press, 2003.

[15] C. Del Cañizo and A. Luque, "Comprehensive model for the gettering of lifetime-killing impurities in silicon," Journal of the Electrochemical Society, vol. 147, no. 7, pp. 2685-2692, 2000.

[16] A. Lin, X. Wong, Y. Li, and L. Chou, "Passivation and gettering of defective crystalline silicon solar cell," Solar Energy Materials and Solar Cells, vol. 62, pp. 149-155, 2000. 

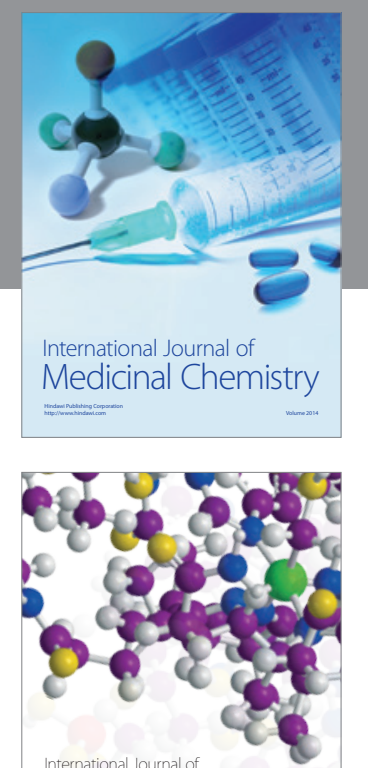

\section{Carbohydrate} Chemistry

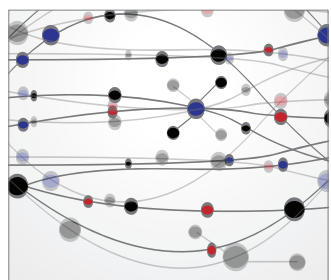

The Scientific World Journal
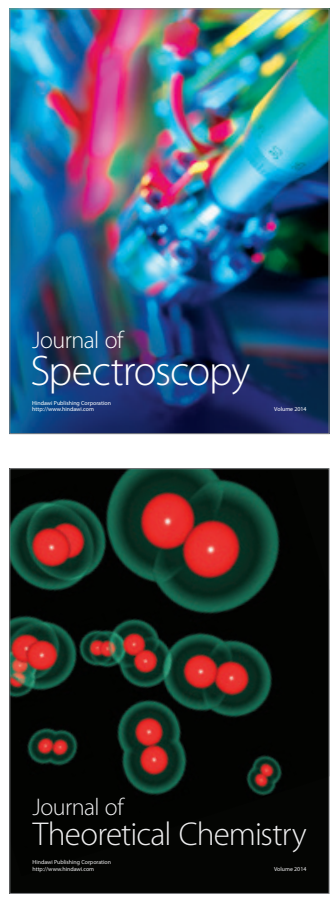
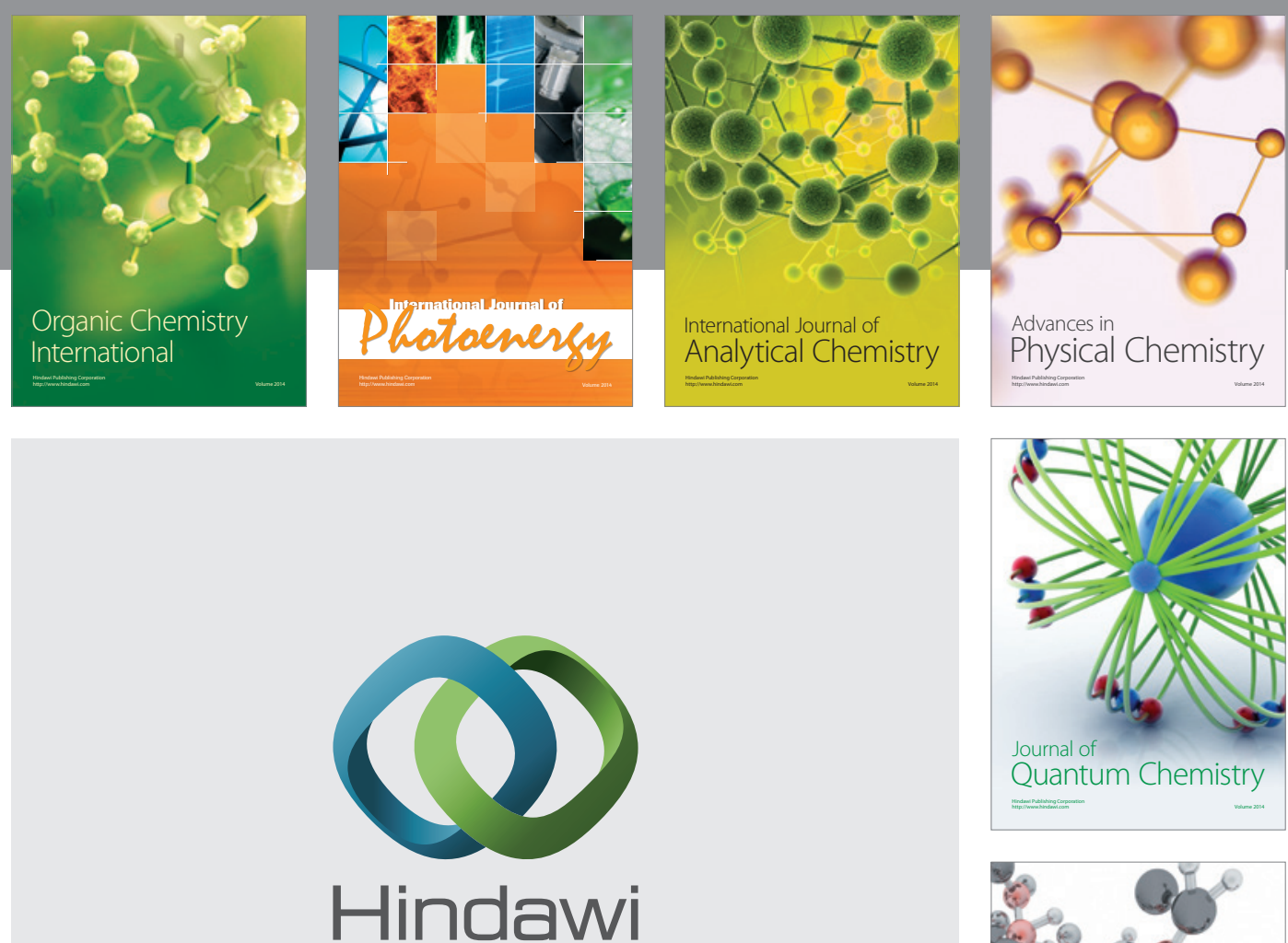

Submit your manuscripts at

http://www.hindawi.com

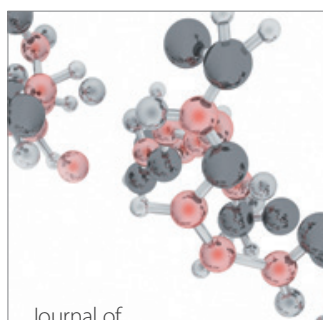

Analytical Methods

in Chemistry

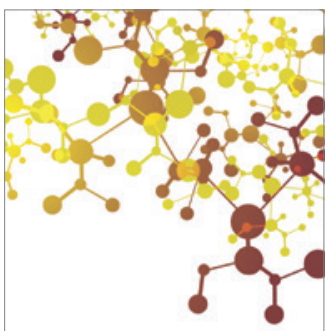

Journal of

Applied Chemistry

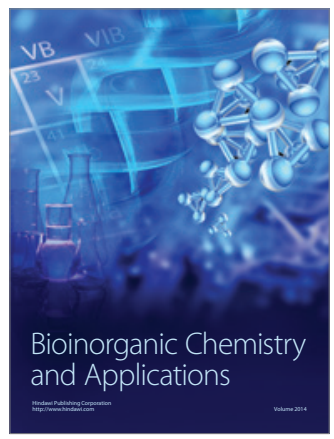

Inorganic Chemistry
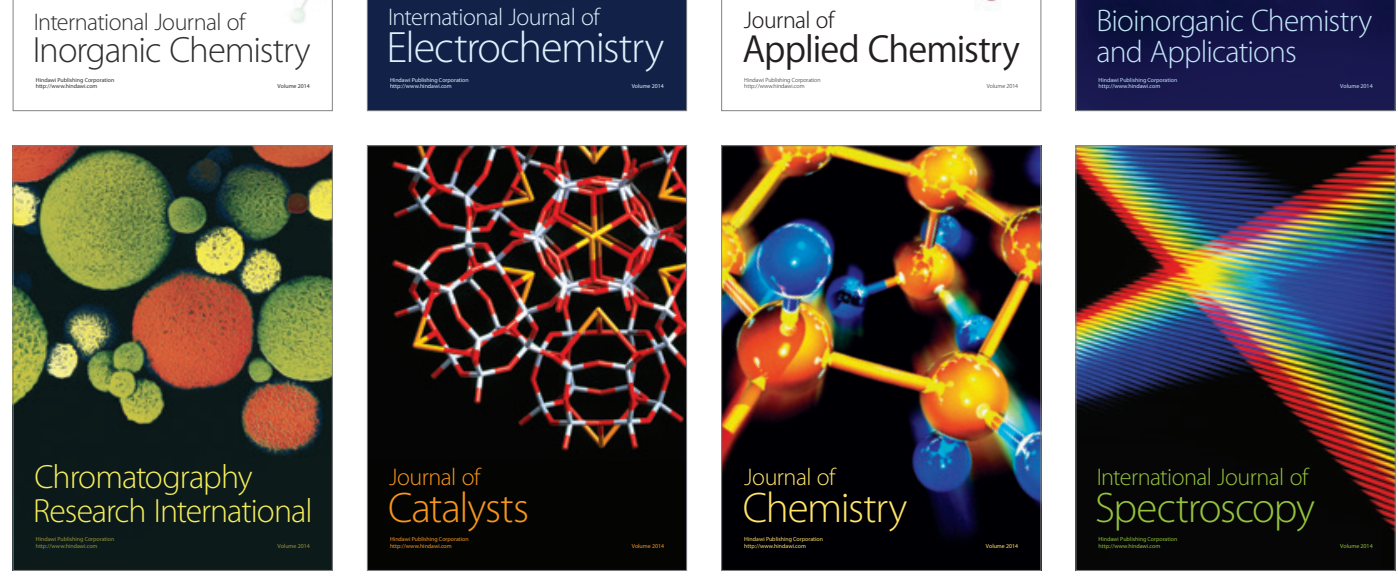